\title{
How people use Rich Pictures to help them think and act
}

\section{Dr Simon Bell}

Communication and Systems Department

Faculty of Mathematics

Computing and Technology

Open University

Milton Keynes MK7 6AA

UK

Email: s.g.bell@open.ac.uk

Professor Stephen Morse

Centre for Environmental Strategy

University of Surrey

Guildford

Surrey GU2 7XH

UK

Email: s.morse@surrey.ac.uk

Groups of all kinds are complex organisations. To understand them and to facilitate them in process terms is a matter of rich and diverse discourse in varied fields from sustainable development to coastal ecology; from bandwidth in rural communities to health service provision. How to allow groups to discourse, problem solve and review their own issues and concerns? Diagrams in general and rich pictures in particular can be great means to allow groups to explore their subconscious, their occult sentiments and conflicted understandings. This paper explores and explains diverse use of Pictures and shows how they can be applied and understood in group processes of all kinds.

Insert Live Scribes Cartoon at this point. 


\section{The history and importance of pictures.}

The place of pictures and diagrams in our cultural life can be said to be as old as human culture itself. From the Chauvet caves of Southern France, to the towering hieroglyphs of Ancient Egypt, from poster art to contemporary cries for help and satirical street art, diagrams and pictures are an integral part of human expression.

Insert Figures 1, 2, 3, and 4 here.

The range of diagrams and pictures is as wide as human experience itself. Diagrams and paintings of all kinds hold a mirror up to human experience. They reveal and hide human interactions and provide mysterious insights into the mind of pan-humanity of all ages. They are windows to the human world.

Our focus here is on the rich picture, a free form type of diagrammatic representation which has a wide role of functions within human artifice, but especially as a tool to help groups arrive at a consensual analysis of a situation. In a more extended work we have discussed the importance of the way in which groups of people make use of diagrams (Bell and Morse 2010). In this brief paper we will provide some background to the antecedence of rich pictures and to the way in which some have used them in groups and for group work. However, our main aim here is to describe in detail how rich pictures can be used to tell the inner most story of the group - sometimes the unconscious and occult story - and can help the group to move forward. Our proposition is that rich pictures are a valuable output in themselves and deserve far greater attention that we perhaps pay them when they are typically seen as but one step within a bigger process.

\section{Groups and Pictures}

There are many different ways in which members of groups can be included within processes of drawing pictures for the purpose of problem solving, and there are many champions of each of these approaches espousing their relative advantages over competitors. The literature is far too large to even attempt to summarise in a paper as short as this, but needless to say that each approach does indeed have its own set of pros and cons, including resources required. We have recently published a book which includes some of this territory (Bell and Morse, 2012), but even with the luxury of more space a review can be bewildering. Which approach is 'best', if such an adjective can be employed in any meaningful sense, will depend upon context and the expertise and experience of those attempting to facilitate the participation. Bad decisions over which approach to take, and indeed a poor implementation of what should be a viable approach, can greatly reduce and even eliminate the value of including stakeholders even if steps (1) and (2) have been done well. One systems approach is the 'Soft Systems' methodology of Peter Checkland (Checkland 1981; Checkland and Scholes 1990). Soft Systems shares the same epistemology of almost all participatory approaches. It primarily provides a space for individuals to interact and share insights and a focus towards problem solving - initially at least by sharing in a diagramming process.

The starting point for Soft Systems is the rich picture . A group is provided with a blank sheet of 'flip chart' paper and a set of coloured felt-tip pens, ideally of different colour. What goes 
into the picture, the form of diagrams, the linkages and colours are entirely up to the group. In effect it provides a tangible (albeit 2 dimensional in physical terms) space for the group to discuss, negotiate, share, and hopefully to arrive at a consensus. The challenge to the group is to represent the problem context in which they are engaged, including what they may see as problematic. Indeed the picture itself is but a reflection of what may be a extensive discourse lasting for some hours, and all the stresses and strains of that discourse as well as conflicts and consensus will be within that picture.

Although practitioner opinion varies, rich pictures have two basic 'rules' designed to help encourage the sharing of insights.

1. the paper has to be visible to all members of the group at all times so it is clear to all what decisions have been made as to the components and linkages within the system.

2. text should be avoided as diagrams are much easier to appreciate visually and take up far less space. A simple 'no entry' sign drawn in a rich picture can be used to summarise what take pages of text to explain.

Other than these two rules the decisions as to what to include and how are left for the group members to sort out with no input from any facilitators who may be present.

\section{Rich pictures - legacy as problem solving devices}

Rich pictures have a long but under-documented heritage, borrowing much from a longestablished sense in the human race that a 'picture paints a thousand words'. The origin of this phrase is not known but is probably multifaceted. It is perhaps epitomised and romanticised in the lyrics of David Gates' song 'If'

"If a picture paints a thousand words,

Then why can't I paint you?

The words will never show the you I've come to know."

After all, people have been painting pictures since the very origins of the human race. Early inspiration for rich pictures within a participatory context is difficult as they appear to gain their inspiration from a number of sources and almost 'emerge' from the literature (for example see: Checkland 1972; Churchman 1979) but rich pictures in all kinds of academic and professional work can be argued to date back to Checkland's original work on Soft Systems in 1975 (Checkland 1975) where he refers to the notion of a rich picture.

"The end point of this stage in the analysis should be a picture of the problem situation, one as rich as can be assembled in the time available" (page 281).

This use of diagrams in Soft Systems obeys rules which have a long and healthy lineage. As Fathulla observes:

"The way people use diagrams, irrespective of the application has been eloquently described by J D Watson, Nobel Prize winner (1968), who discovered the structure of DNA: ".. drawing and thinking are frequently so simultaneous 
that the graphic image appears almost an extension of the thinking process." (Fathulla 2008)

Using diagrams as a means to aid the thinking process is now a well-trodden path with visualisation techniques such as mind maps (Buzan 1992; Marguiles and Maal 2002), road maps (Phaal, Farrukh and Probert 2009) and other forms of graphic representation. This was also expressed in Checkland's seminal volume in 1981 (Checkland 1981) although, interestingly, the only citation to rich pictures in the book is to a glossary definition of it on page 317 - there being no substantive use of the diagrams in the text itself. We remain unsure as to what this tells us; maybe it reflects a sense of the 'obviousness' of the need to use pictures.

Soft Systems has undoubtedly been a great contemporary catalyst for rich picture use but maybe the key development for the wider appreciation of rich pictures themselves was provided by the Systems Group at the Open University who both explored the use of the diagramming method in courses (Open University 1987; Open University 1997; Open University 2000; Open University 2000).

But what are rich pictures? Lewis has provided an early assessment of the origins and morphology of the rich picture idea (Lewis 1992). Lewis also indicates a range of confusions over the development and use of the pictures, mainly in terms of the way in which they are adopted within the rules of Soft Systems use. For the purposes of this paper soft systems is not of specific interest, we are far more concerned with the value and use of rich pictures as free standing, problem diagnosing tools and what they can tell us about the work of the groups that created them. In the 2004 Information Systems Toolkit course, rich pictures were described as follows:

"... it is often useful to have the bigger picture and the maze of processes and structures operative in the context gathered together in one format.

In cases like this the rich picture is a powerful aid to understanding and, used in a participative manner, it can assist teams to gain a better appreciation of the issues which confront them.

Purpose

Rich pictures are drawn at the pre-analysis stage, before you know clearly which parts of the situation should best be regarded as process and which as structure. Rich pictures (situation summaries) are used to depict complicated situations. They are an attempt to encapsulate the real situation through a no-holds-barred, cartoon representation of all the ideas covered already - layout, connections, relationships, influences, cause-and-effect, and so on. As well as these objective notions, rich pictures should depict subjective elements such as character and characteristics, points of view and prejudices, spirit and human nature. If you are working with a client you should try to draw these from the actors themselves, at least initially, rather than focusing on your own interpretation of the situation." (T851 Diagramming). 
In a course recently produced at the Open University (TU811 Thinking Strategically: systems tools for managing change) in Part 4 the authors say of the rich picture process:

"You will read more about the use of rich pictures (hand-drawn sketches of what each individual perceives to be going on in a situation) in the SSM section which follows this. Drawing rich pictures can return you to the simplicity of a childhood vision where you mirror directly what you observe, and in that process reveal how you feel about it. This seems to bypass the mental filters which tend to frame that vision in terms of the generally accepted story, or to obscure the things it is hard to say without offending. The use of humour and imagery make it possible to say things it is otherwise difficult to raise; they can provide a space within which you have licence to say something that would otherwise be taboo. Describing what you have drawn in your rich picture feels more like bravely admitting how things looks to you, than asserting your view as a perhaps threatening statement about reality. "

A theme arising from the nature of rich pictures is the 'surfacing' and 'exploratory' element. Rich pictures would appear to be a means to almost 'trick' the individual or the group into an examination of cryptic (hidden meaning), arcane (pertaining it the inward or mystical) or occult (hidden secret) aspects of the individual or the group. In total, the picture is an acroamatic device. In an earlier paper, the authors referred to this function with reference to holistic project understandings:

"we can imagine an 'holistic' project as the exact opposite of the conventional and this would certainly constitute the discovery of an alternative and acroamatic story as opposed to the conventional, dominant project narrative" (Bell and Morse 2007 page 105)

But it is important to note that rich pictures are often employed as a step in a process; a 'way point' towards a goal. The analysis which emerges is not an end but a beginning; it feeds into the next step which encourages groups to look at their analysis and focus on what they think are the most important elements. Thus rich pictures have a transience, perhaps even a sad transience, in that they become left behind as the group strives to 'do' the next stage of the process. The rich picture may be left on the table or perhaps put up on a wall, as a reminder, but the context has been captured and bottled and the group moves on. As frequent workshop facilitators we have often felt a sadness at this. The rich pictures contain so much insight, not just about the system but also about the group, and it seems almost wasteful to encourage groups to tease out 'bits' of the picture for more detailed follow-up and to leave out the rest. It is this thinking that has helped spur this paper.

\section{Rich pictures in Action}

To illustrate what we mean by the statement towards the end of the previous section we show what we would call an 'archetypal-if-poor' rich picture drawn from one of our workshops in the UK (Figure 6. The picture was created by a group of people working in the UK's National Health Service (NHS). At this point we make no attempt to interpret the picture's meaning but the relative poverty of the content is evident in: 
- A relative simplicity of visual metaphor (much of the picture - 9 incidents in total - is devoted to 'stick' people and sheets of paper)

- Lifeless and detail-shy depiction of important people (5 of the 9 incidents of people employ stick characters of the same size and there is little attempt to differentiate, even in terms of characteristics such as male/female let alone their importance within the system)

- Occasional use of words (including 'staff' and 'patients')

- A lack of a central theme or visual concept to guide the viewer/reader (people who produced the picture are represented in the centre but it is not immediately apparent what the key components and issues are within the system)

- Poverty of colour and line width (4 colours are employed, but note how the colour red is employed towards the left-hand side of the picture, perhaps indicating that the person standing at that place held onto the red pen! Also note the absence of lines connecting the components).

Insert Figure 5 about here

These observations, whilst remaining true should not detract from the usefulness the authors found in the picture and some of the important outputs which followed later on in the process from drawing it. Despite the picture offering little in terms of visual content, it nevertheless had a capacity to galvanise the group which drew it and, tellingly, allowed the group to raise issues, via the picture, which they perhaps would not discuss or write about acroamatic: hidden and occult issues. Some good examples include:

- Anxiety over measurement. The presence of a large abacus at the top left indicating the perceived importance of 'counting' (money, indicators of performance etc.) in the system.

- Anxiety over litigation? Patients, even the dead ones, are being portrayed as 'happy'.

- Anxiety over private practice? Concern is shown over senior medics spending time in non-work related activity (symbolised by the golfer)

These are very big issues indeed and have been at the heart of major discourses over the future of the NHS in the UK. Indeed the picture also embodies something about the group with the senior member being portrayed in an almost 'Zen-like' position in the centre of the picture. Thus even in this apparently simple example of a rich picture there are so many messages and meanings. 
Our next example is a rich picture drawn by a group of Chinese Financial Managers.

Insert Figure 6 about here

The picture shows governments (UK and Chinese), teams, difficulties between team members and new ideas coming into being. All these are obvious and explicit aspects of the context. However, the picture also shows broken team dynamics, intrusive monitoring and financial corruption. We speculate that these are not elements which we could easily get any Chinese Manager to talk or write about in public. Certain occult rules begin to emerge for rich pictures. We can set these out as hypotheses as follows:

H1. Rich pictures provide an opportunity for optimal indiscretion

H2. Those that make use of this may do it explicitly and consciously or implicitly and unconsciously.

H3. Rich pictures therefore allow groups to express themselves in ways which are unusual and challenging

H4. Rich pictures can be expressions of the inner life or 'soul' of the group.

H5. Rich pictures can be analysis tools which allow us to understand what a group really thinks about a very difficult problem.

Indeed the two examples of rich pictures portray such richness that it is tempting to stop the process at that point and analyse in some depth as to what they are telling us. In workshops, of course, there may not be the luxury of time to do this. Indeed, the funder providing the resources for the workshop is most usually interested solely in the final outputs; what must be done to help address any problems identified by the group so as to make things 'better'? The workshop is just a means to get those answers and nothing more. Arriving at answers to the hypotheses raised above may simply not be on the radar. Hence the reflection typically amounts to a brief presentation by the individual or group that produced the rich picture, rapidly followed by the next stage of the process which encourages them to only focus on one or two aspects of the picture for the rest of the workshop. Indeed, and perhaps ironically, the richness of what is in the picture almost becomes inconvenient in our haste to get to things which we can deal with via recommendation to the workshop 'owner'.

\section{Analysing Rich pictures}

But if we can introduce hiatus at this point of the workshop and thus allow space to step back and analyse the rich pictures then how can this be done? Just what can they tell us about the issues being explored and the people doing the exploring? Well it has to first be noted that human beings have been appraising pictures since they were first drawn on the ground and on stone so it has hardly a new topic. But are their insights from other bodies of 
knowledge that can help us here? Considering rich pictures as art, James Carney (1994; pages 13-14) points out:

"Almost everyone at some time or another engages in art criticism. And there is a plurality of critical games. An examination of the diverse practices of art critics fails to reveal any established structure or method, much less any type-relative criticism tied to some analytical sequence".

Other scholars have also looked at the process of criticism. Barrett (1994) represents it as 'interpretation' and sets out an 18 point set of principles which, in a common sense manner can guide any assessment. Key to Barrett's principles are:

1. Artworks have "aboutness" and demand interpretation.

2. Interpretations are persuasive arguments.

3. Some interpretations are better than others.

4. Good interpretations of art tell more about the artwork than they tell about the critic.

5. Feelings are guides to interpretations.

6. There can be different, competing, and contradictory interpretations of the same artwork.

7. Interpretations are often based on a worldview.

8. Interpretations are not so much absolutely right, but more or less reasonable, convincing, enlightening, and informative.

9. Interpretations can be judged by coherence, correspondence, and inclusiveness.

10. An artwork is not necessarily about what the artist wanted it to be about.

11. A critic ought not to be the spokesperson for the artist.

12. Interpretations ought to present the work in its best rather than its weakest light.

13. The objects of interpretation are artworks, not artists.

14. All art is in part about the world in which it emerged.

15. All art is in part about other art.

16. No single interpretation is exhaustive of the meaning of an artwork.

17. The meanings of an artwork may be different from its significance to the viewer. Interpretation is ultimately a communal endeavour, and the community is ultimately self- corrective.

18. Good interpretations invite us to see for ourselves and to continue on our own. (adapted from: Barrett 1994)

These views concerning interpretation as persuasive argument, feelings as guides, worldviews underlying interpretation, interpretation not being 'right' and the unintended outcomes and consequences of art apply as well to rich pictures as to any other form of representation (pictorial or otherwise). 
If Barrett sets out some of the ground rules for interpretation, Carney sets out 7 sequential steps which he believes can be applied to analyse a picture and these have been summarised as Table 1 . Please note that we are certainly not trying to pass any judgement here as to whether Carney's approach is any better than other approaches that attempt to set out to set out the critical process. To some extent his is a proceduralised attempt to achieve what Barrett was explaining. Neither can we claim that Carney was the first to do such a thing. Thomas Munro published his famous work entitled the "The Scientific Method in Aesthetics" in 1928 which set out a positivist view of art criticism. Hungerland in 1947 suggested that art be categorised based upon certain criteria and then assessed within those categories. Indeed Clements in 1979 already bemoans what had already become a burgeoning series of efforts to apply 'scientific' methods to an analysis of art:

"It seems that the scientific method has been applied to all manner of non-scientific, affective concerns such as social intercourse, religion, and value acquisition. Thus it is not surprising, though it may seem repugnant to many, that an attempt should be made to apply the scientific method to art criticism, an area many hoped would remain a sanctuary, safe from systematizing classification laws. (Clement, 1979; p 67).

Repugnant to many it may be, but he goes on to make his own contribution towards such positivist frameworks by raising points such as:

"for criticism of a work of art, it is essential to analyze the colour, shape, space, line, texture, pattern, light; the way these mutually interconnect (e.g., colourful shapes, space-creating lines); and the way they are bound together by the principles of design: rhythm, progression, repetition, balance, and variation. As the literal, technical, and formal features are being inventoried, a bridge between formal analysis and interpretation should develop." (Clements, 1979; p 71).

More recently, Van Meel-Jansen (2006) suggests the following criteria be employed when appreciating art:

\section{Attraction}

2. Representation and realism

3. Emotional expression

4. Style and form

5. Interpretation

She refers to this as the 'Magical Number Five' in art appreciation and even goes on to describe how these criteria when applied as an analytical framework can be used to make comparisons between different categories of people in terms of how they appreciate a 
single piece of art. Thus we are almost into a deductive process of hypothesis setting and testing.

Considering comic art, Scott McCloud suggests six levels of interpretation in the assessment of diagrams:

1. Idea /purpose

2. Form

3. Idiom

4. Structure

5. Craft

6. Surface

(McCloud `1993)

Even with the few examples provided here it is apparent that there is a well-established literature on the structured interpretation and critical appraisal of art although this has not previously been connected to the literature on soft systems or other problem solving methods that employ pictorial representation. This lack of connection is perhaps not all that surprising given that these literatures have no other obvious points of connection, but our contention is that this can be drawn upon in the interpretation of rich pictures.

Insert Table 1 about here.

There is certainly a positivist feel to the approach in Table 1 it and perhaps it is fair to say that it only sets out what an experienced critic would instinctively look for in a picture rather than going through a mental step-by-step process as suggested here. Thus an experienced art critic would 'feel' the point made in Table 1 in much the same way that an experienced facilitator would 'feel' whether a group has produced a 'rich' rich picture or worked well together. The latter might not openly say so, of course, but hand on heart how many times do we do this during workshops? Table 1 certainly has a logical appeal even if Carneys 1994 paper is by no means the only academic writing or the last word on this topic.

The steps set out by Carney (1994) and summarised in Table 1 can be applied to rich pictures and a column has been added to the table in order to make that connection. Rich pictures are not intrinsically any different in form from what Carney has in mind other than they have been produced under different circumstances (relatively quickly, perhaps by a group rather than an individual) and for a different reason (to analyse a given problem or issue which might be quite specific). Even so one can still look at their context, their content and so on. In order to illustrate this, Figures 8 and 9 present rich pictures which were developed in recent research which we undertook in Slovakia as part of the EU Framework 7 
funded project called POINT (POlicy Influence of iNdicaTors; contract no 217207) which began in 2008. The rich pictures were produced by two groups in Slovakia, although the workshops of which the groups were a part happened at different times and had different themes (although the venue was the same). Each group had 4 to 5 members (there was some fluctuation during the two days of workshop), and the rich pictures were generated as the very first event of day 1 ; once the participants had been given a presentation as to what to expect over the 2 days. The group generating Figure 8 were asked to explore the influence of indicators in sustainable development in Slovakia; a very broad question which gave them lots of freedom in terms of deciding what they meant by sustainable development, indicators and indeed influence. The second group were given a similar task but this time somewhat more focussed on the influence of indicators in the agricultural sector. Agriculture is an important sector within sustainable development but is by no means the only one. The groups mostly comprised professionals working in the relevant public sector agencies as well as university-based researchers and postgraduate students. Each of the two groups was balanced in terms of men and women, and for the most part they had not met prior to the workshop although some may have communicated in the course of their work. It is not necessary here to go into the details of the groups and their dynamics but the interested reader is referred to Bell and Morse (2012) where this is discussed in some depth. Once the rich pictures had been produced the groups were given a chance to talk through them and explain what they represented and what insights they generated. This was usually undertaken by one of the group members, but could involve comments from other members of the group.

Insert Figures 7 and 8 here.

The rich pictures in Figures 7 and 8 are clearly very different and clearly represent very different concerns and backgrounds (for more detail on interpretation of the group which produces the rich picture see: Bell and Morse 2012) however, applying Carney's dictum certain observations can be made.

Insert Tables 1 and 2 here.

In the use of Carney's seven steps we have made an interpretative 'leap' to the assessment of the rich picture content and you will see we have 'interpreted' as Barrett would see it, from our own world view stance. We, as the consumers of the rich picture narratives, and the interpreters of meaning, have our own sense of the pictures. In this sense, our interpretation is as 'right' as anyone else's but, and back to Barrett here, if the interpretation is 'communal', rich pictures need to be seen and interpreted and argued over by the community in order for the 'self-corrective' process to begin. There are echoes here to points made by Lankford (1984) as one of his eleven 'Propositions for Art Criticism' is that "Interpretations are verifiable within an inter-subjective context" (page 155); meaning in 
basic terms that it is important to compare notes with others on the same art. He goes on to say that:

"If two or more people engage in critical dialogue centered around a work of art, the perceptual experience of each person may serve to revise the interpretation of the work for others. While no single interpretation can describe the total range of ideas a work of art can support, it is possible that varying interpretations can be combined into an enriched interpretation." (page 155)

Taking all this into account, our interpretation is that Figure 7 can be regarded as a 'better' rich picture than that of Figure 8 . Our main ground for making this assessment is the focus of the second picture on 'issues' (albeit important ones such as pollution) rather than the key theme of the event where the picture was drawn - influence of indicators - which were largely absent. Of course, this does not make the picture 'poor' in a wider sense. It clearly represents strong views and is a very active and vivid production. Purely from the point of the view of the purpose for which it was originally intended, it can be seen as being poor as it misses the main point of the exercise.

\section{Discussion}

Returning to our five hypotheses in the light of the interpretation of the two Rich pictures making use of Carney's dictum:

H1. Rich pictures provide an opportunity for optimal indiscretion. We can see this most clearly in Figure 8 - where the 'hidden' thoughts of the group have made manifest. The group can 'hide' in the anonymity of the process and be indiscreet about the main question. In this case, this indiscretion provides the insight that not all indicators are equal, that some are more equal than others and that the weaker indicators, which may be just as if nor more important than the strong ones, may need to 'hide' in order to exist at all.

H2. Those that make use of this may do it explicitly and consciously or implicitly and unconsciously. We are not aware of the groups acting consciously to express their concerns and anxieties. We understand, from our interpretation of the pictures, that both groups drawing Figures 8 and 9 explored on the boundaries of their knowledge but that the dynamics of the groups during the workshops indicated periods of explicit cooperation and sharing and periods when members of the groups went 'quiet' and certain dominant voices 'took over'. This fluctuation between periods of what can be regarded as 'good group work' and 'bad group work' (for want of a better phrase) is indicative of periods of conscious engagement and conscious disengagement from the rich picture task.

H3. Rich pictures therefore allow groups to express themselves in ways which are unusual and challenging. Certainly our field notes indicate that both groups undertook the drawing task but were at first challenged by the nature of the task (this is usually the case). In the 
challenge of the picture, the challenge to draw that which would normally be written, discussed or avoided, the groups were certainly challenged.

H4. Rich pictures can therefore be expressions of the inner life or 'soul' of the group. Certainly in the case of Figure 8 this holds. The group put great conscious and emotional effort into the 'cave'. The sense of an injustice and a 'stupid outcome' was very pertinent as the group grappled with the notion of a good idea which was to some extent suppressed by conventional indicator norms.

H5. Rich pictures can be analysis tools which allow us to understand what a group really thinks about a very difficult problem. Again, if $\mathrm{H} 1-4$ hold true for a group then $\mathrm{H} 5$ also emerges as a common sense outcome. The picture, if it allows a group safe access to its hidden views, allows the group to explore difficult things and promotes the engagement with complexity, de facto the rich picture will result in the group being facilitated in doing difficult work.

But what about the critical appraisal of the content set out in the rich picture artifice? Well, even with the two examples we have provided it can be seen how the use of the framework in Table 1 generates a different set of insights. The pictures really are 'rich' in terms of what they tell us about the ways in which the groups approached the questions they were asked. One group stuck to the theme and developed some interesting and novel insights into indicator use. The other group produced something far more one-dimensional and hence limited in terms of new insight and ideas. Why was that so? There is no space to talk about this here but it was interesting to note that the dynamics of the two groups was also quite different. The group that produced the rich picture shown in Figure 8 were active throughout the process and there was clearly much engagement between the members with no one dominant voice. With the group producing the rich picture shown in Figure 9 this dynamism was far less evident and the group was more laboured in its approach. They also did not have a dominant member and were clearly struggling and the result was perhaps a retreat to the more 'well known' and established facets of the issue they were asked to explore. For the interested reader we have developed this observation much further in Bell and Morse (2010, 2012).

The final point that needs to be made is that while rich pictures are the tangible manifestation of the insights arrived at by the group we should not lose sight of the fact that the interactions between the members can be valuable in itself. Even if the rich pictures that result can be deemed to be 'poorer' than others there can still be valuable learning and networking that took place within the group. In the same way that an artist can learn much within the process of creating art, even if the product may not be regarded by critics as making a significant contribution, then so can groups also gain much from the process. Thus we do need to be careful about being too dismissive about the quality of outputs as this can also be dismissive about process. As Pablo Picasso once said:

"I am always doing that which I cannot do, in order that I may learn how to do it. " 


\section{Conclusion}

A central tenant of this paper is that rich pictures deserve to be seen as much more than just 'waypoints' within a bigger picture of analysis by groups. They can be valuable outputs in and of themselves and deserve much more attention than perhaps we give them. It is perhaps telling that there are very few publications devoted solely to the study of rich pictures, and indeed our own paper Bell and Morse (2010) is one of the very first to do this although even here we have not gone so far as to show how rich pictures can be analysed using the sort of framework set out in Table 1. We readily admit that Carney (1994) might not provide the best or most appropriate framework to apply to rich pictures and the reader may well be able to come up with alternatives, but it is the principle of value in such exploration that we wish to establish rather than how it should be done. We also recognise that this in-depth reflection on one output may not be possible during the 'hot house' which workshops tend to represent. In the Slovakia workshops time was very limited, as it so often is, and while the rich pictures were the first outputs on day 1 the groups were moved rapidly on to the next step in the process. We had our focus squarely upon making sure the workshops 'delivered' what was required for the POINT project and set out in the proposal 'blueprint'. We did try to close the circle by bringing them back to rich pictures at the end of the workshop; groups were asked to produce a new rich picture representing how the system would look if their recommendations were implemented. The results of this 'what if' presentation of conclusions was mixed and typically took the form of a description rather than an analysis. Hence they were simpler in terms of content. But even so there was no time during the workshop to stand back and dissect the rich pictures that had been produced by the groups in a thorough manner.

Finally, our working conclusion, going forward, can be expressed as follows:

The human project is not one of segmented realities, rather it is one of multiple perspectives within a multi-verse. Ironically, it would appear that one of the best means to capture and learn and share these perspectives in this multi-verse is the application and free interpretation of a picture format which is one of the most ancient forms of human expression (as witnessed by the paintings of Chauvet) for which we have evidence. 


\section{References}

Barrett, T. (1994). Criticizing Art: Understanding the contemporary. Mountain View, California. , Mayfield Publishing Company. .

Bell, S. and S. Morse (2010). "Rich pictures: A means to explore the 'Sustainable Mind'?" Sustainable Development Wiley Online.

Bell, S. and S. Morse (2012). Resilient Participation: Saving the Human Project? London Earthscan.

Buzan, T. (1992). Use your Head. London, BBC Publications.

Carney JD (1994). A Historical Theory of Art Criticism. Journal of Aesthetic Education, 28(1), 13-29

Checkland, P. (1972). "Towards a Systems Based Methodology for Real-World Problem Solving." Journal of Systems Engineering 3(2): 87-116.

Checkland, P. (1975). "The Development of Systems Thinking by Systems Practice - a methodology from an action research program." Progress in Cybernetics and Systems Research 2: 278 - 283.

Checkland, P. B. (1981). Systems thinking, Systems Practice. Chichester, Wiley.

Checkland, P. B. and J. Scholes (1990). Soft Systems Methodology in Action. Chichester, Wiley.

Churchman, C. W. (1979). The Systems Approach: revised and updated. . New York, Dell Publishing Co. Inc. .

Clements RD (1979). The Inductive Method of Teaching Visual Art Criticism. Journal of Aesthetic Education 13(3): 67-78

Fathulla, K. (2008). "Understanding Diagrams: a pointer to the development of diagramming software." Visible Language 42(3): 265 - 284.

Hungerland H (1947). Suggestions for Procedure in Art Criticism. The Journal of Aesthetics and Art Criticism 5(3): 189-195

Lankford EL (1984). A Phenomenological Methodology for Art Criticism. Studies in Art Education 25(3): 151-158

Lewis, P. J. (1992). "Rich picture building in the soft systems methodology." European Journal of Information Systems 1(5): 351 - 360.

Marguiles, N. and N. Maal (2002). Mapping Inner Space. Thousand Oaks, CA, Corwin Press.

McCloud, S. ('1993). Understanding Comics: The invisible art. New York, Harper Collins Books.

Munro T (1928). Scientific method in æsthetics. W. W. Norton \& company, inc.,

Open University (1987). T301 - Complexity Management and Change: a systems approach. Open University Systems Group. Milton Keynes., The Open University Press.

Open University (1997). Management Information Systems T843. Milton Keynes, Open University.

Open University (2000). T306 Managing Complexity: a systems approach. Milton Keynes, Open University.

Open University (2000). T552: Systems Thinking and Practice: Diagramming Milton Keynes, Open University

Phaal, R., C. Farrukh and D. Probert (2009). "Visualising Strategy: a classification of graphical roadmap forms." International Journal of Technology Management 47(4): 286 - 305. 
Van Meel-Jansen, A. (2006). The Magical Number Five in Art Appreciation. Empirical Sudies of the Arts 24(1): 107 - 118. 
LiveScribes Diagram /cartoon of the Bell Morse Paper

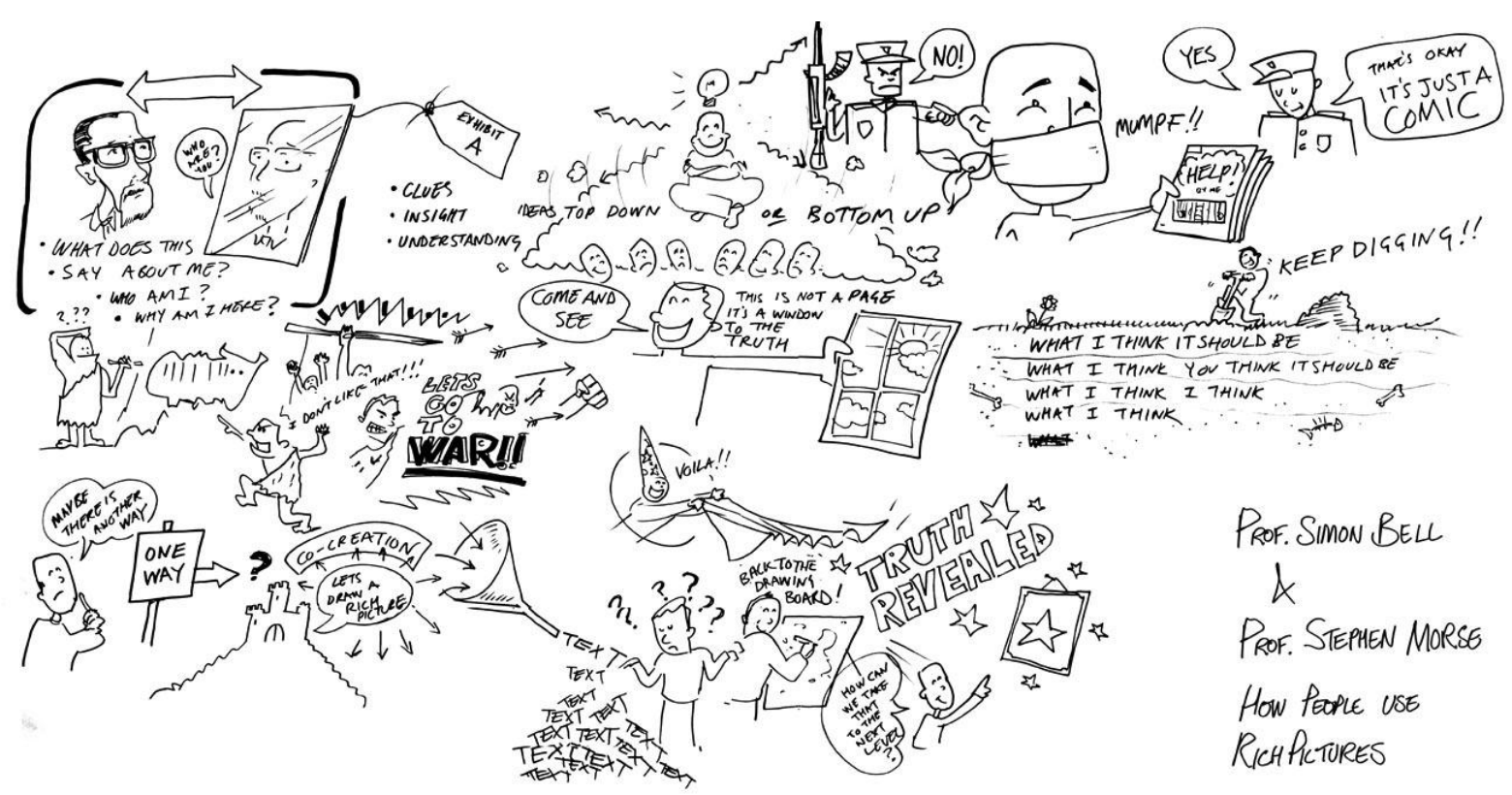


Figure 1. Chauvet Cave Painting

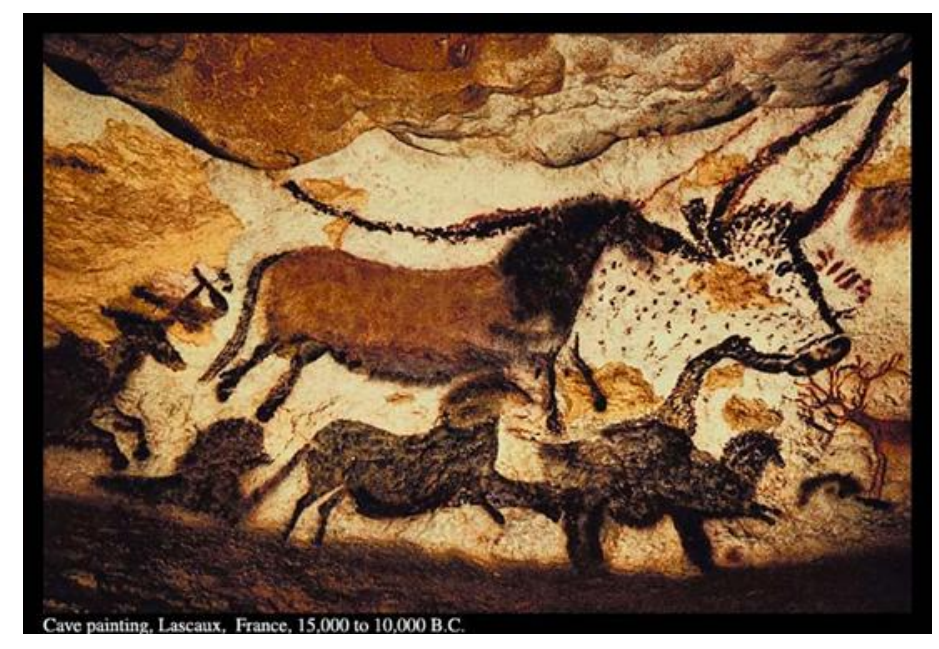

Figure 2 Egyptian Hieroglyphic

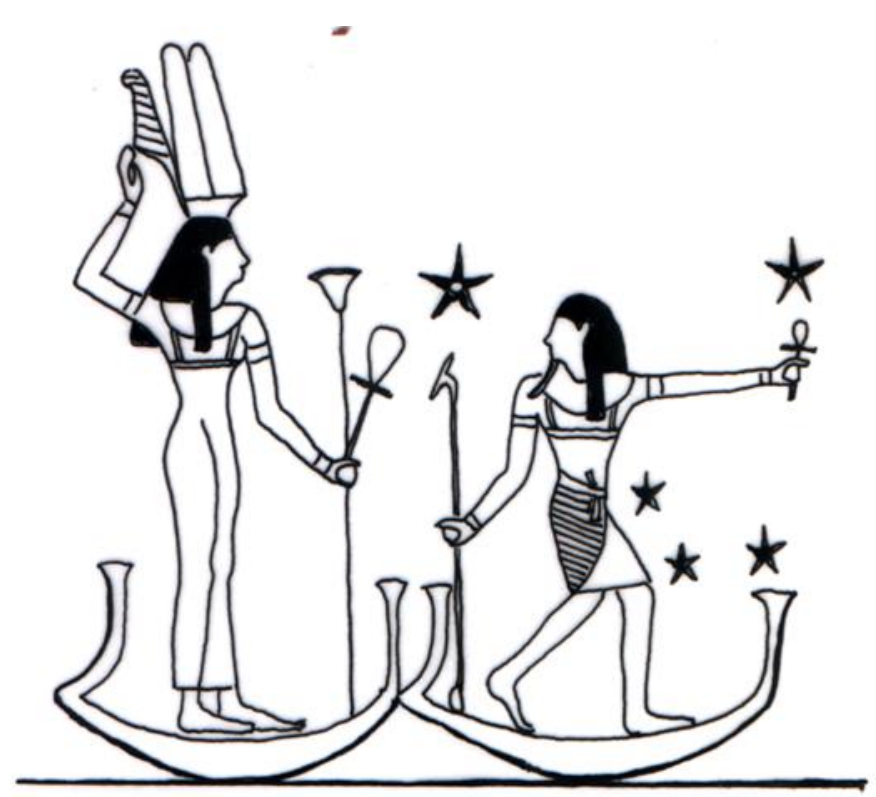


Figure 3 Human street poster

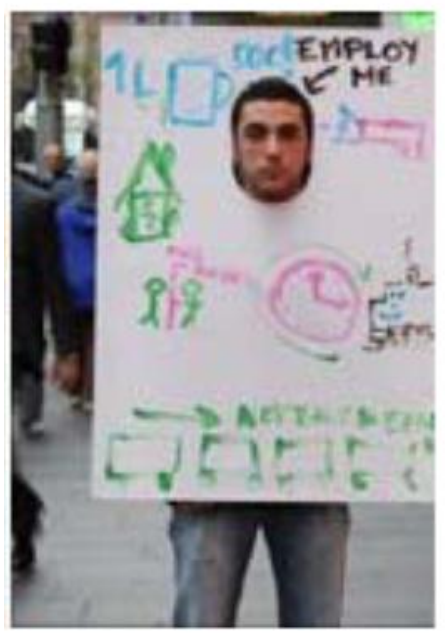

Figure 4. Graffiti

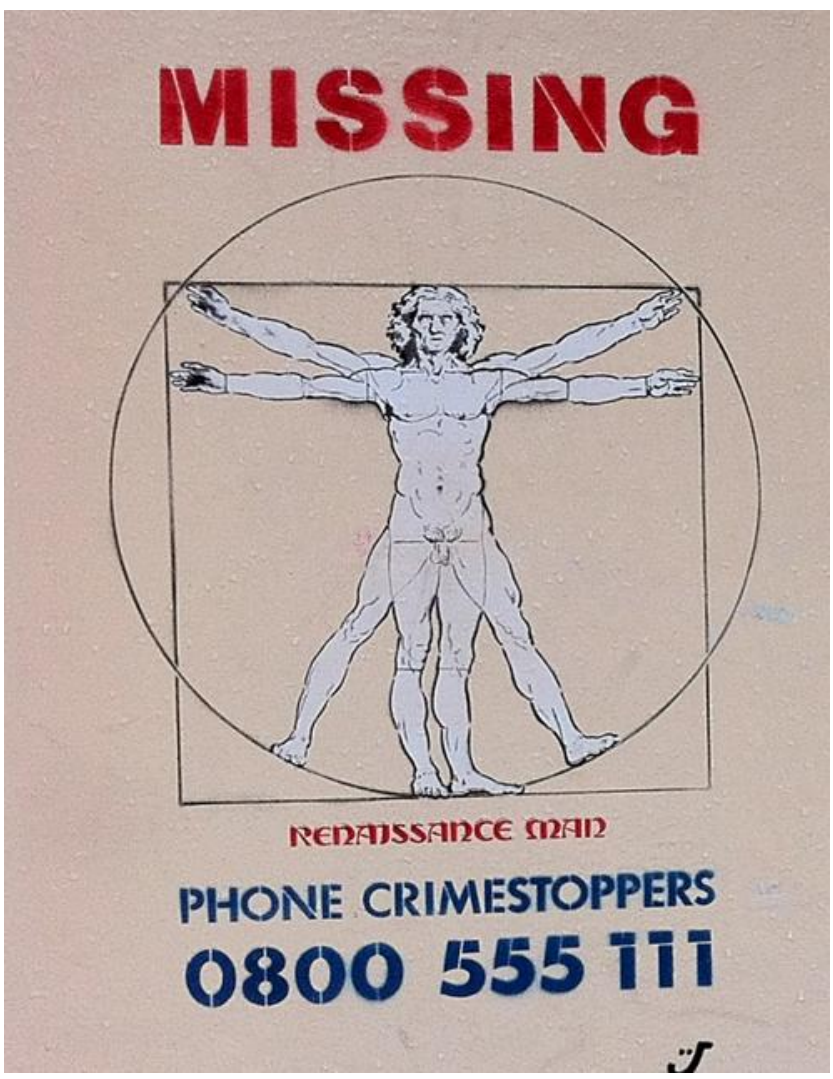


Figure 5. NHS Rich picture

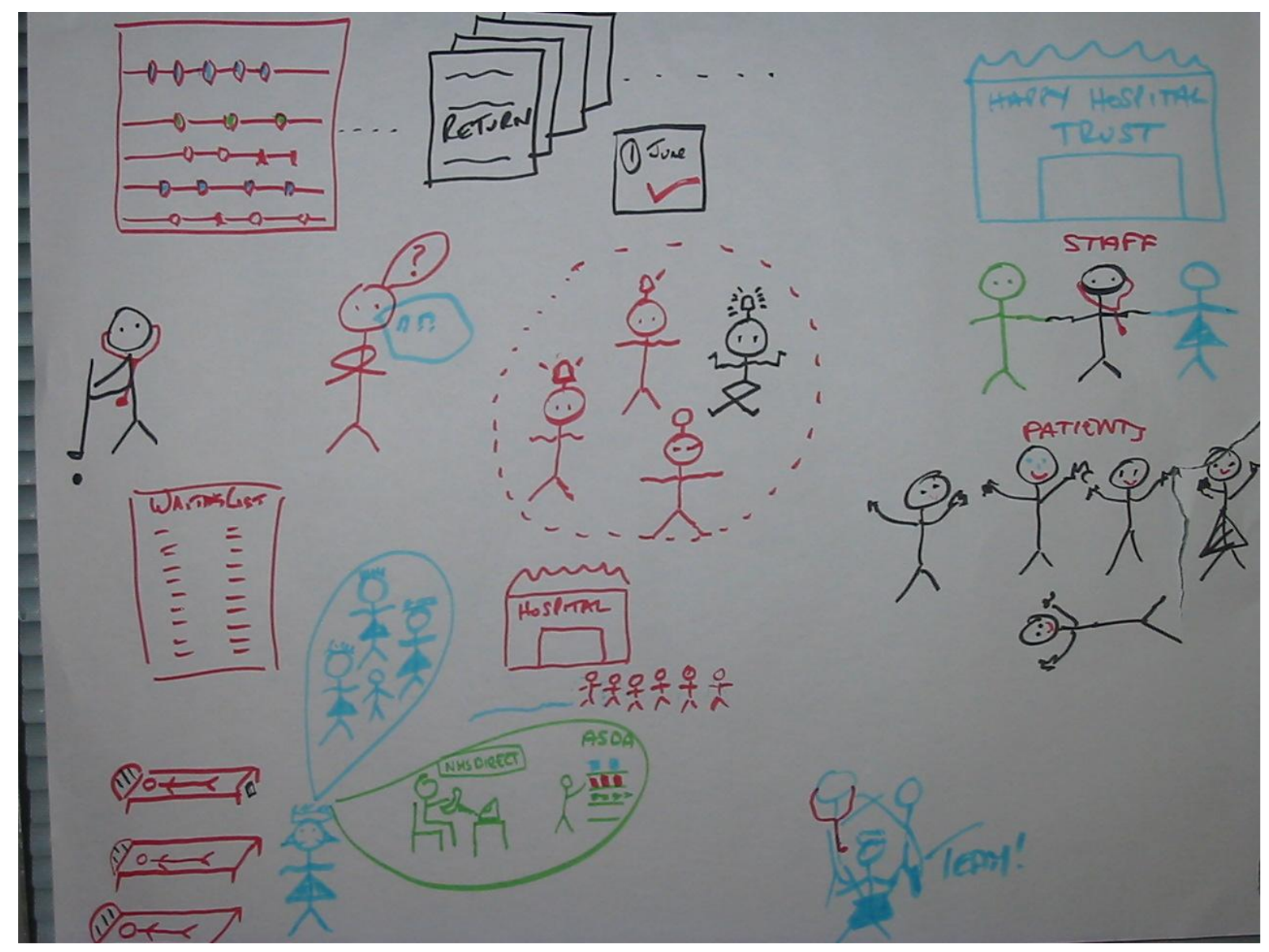


Figure 6. Chinese Rich picture

\section{pich Picturo}

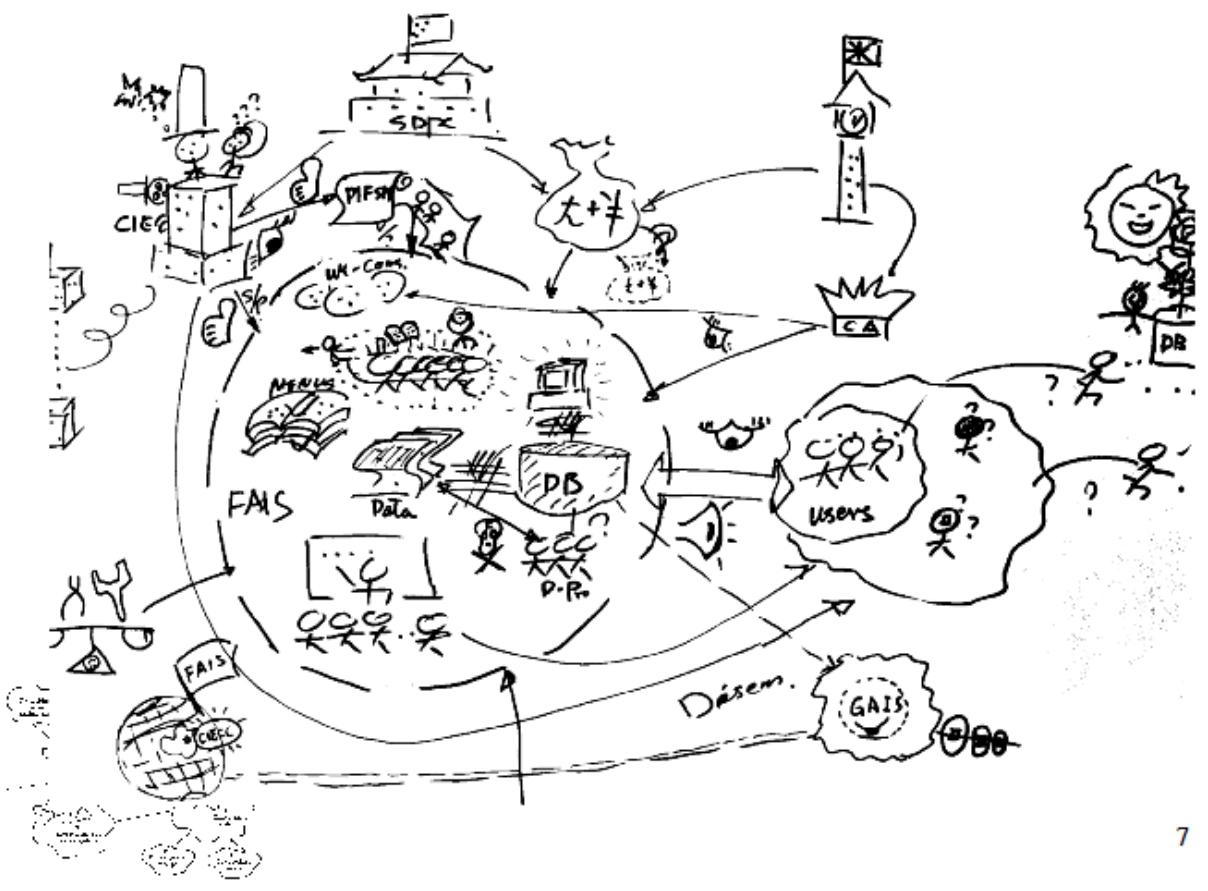


Figure 7. Slovakian rich picture A.

Theme is the influence of indicators in sustainable development in Slovakia

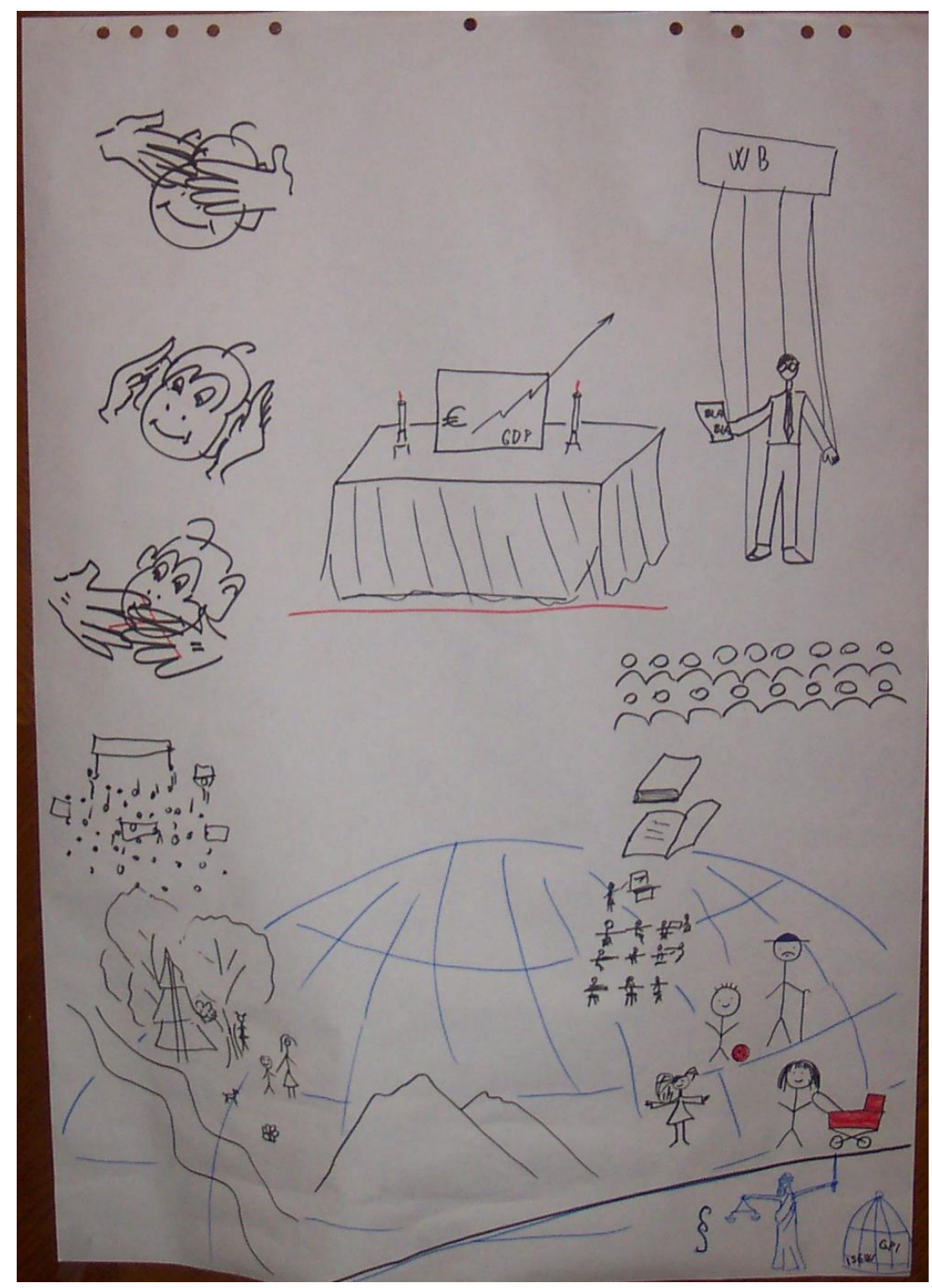


Figure 8. Slovakian rich picture B

Theme is the influence of indicators in the agricultural sector in Slovakia

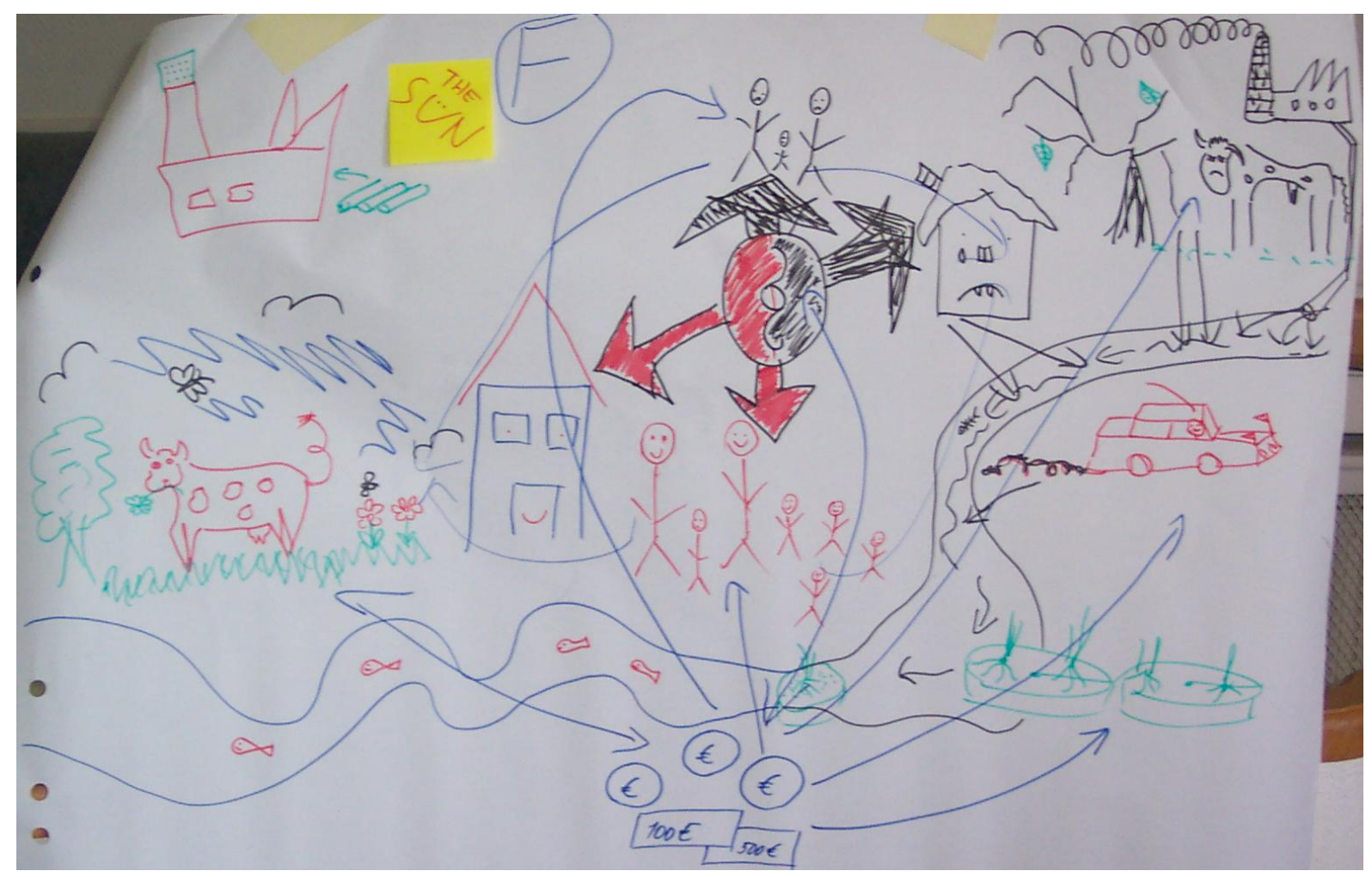


Table 1. The analytical framework for art set out by Carney (1994) and how it could apply to rich pictures.

\begin{tabular}{|c|c|c|c|}
\hline Step & Name of step & Notes & Rich pictures \\
\hline 1 & Locate the Style & $\begin{array}{l}\text { Note the art-historical context and its } \\
\text { characteristic features upon which the } \\
\text { content of the piece depends. }\end{array}$ & $\begin{array}{l}\text { The context of the RP; the problem or system being } \\
\text { analysed }\end{array}$ \\
\hline 4 & Value Features & $\begin{array}{l}\text { These encompass aspects of both form } \\
\text { and content. For example, the } \\
\text { relationships of features in the picture. }\end{array}$ & $\begin{array}{l}\text { Linkages between the elements of the RP; whether } \\
\text { the components are isolated or grouped. }\end{array}$ \\
\hline 5 & Low-level Interpretation & $\begin{array}{l}\text { The meaning or content of } \\
\text { the picture in a basic form }\end{array}$ & $\begin{array}{l}\text { The overall content of the picture; is it narrow in } \\
\text { focus or does it encompass many points? }\end{array}$ \\
\hline 7 & Critical Judgment & $\begin{array}{l}\text { Whether the picture has (or lacks) } \\
\text { aesthetic value to a degree and whether } \\
\text { the artwork has more (or less) value } \\
\text { than another. }\end{array}$ & $\begin{array}{l}\text { Some overall sense of the quality of the RP which } \\
\text { emerges from all of the above. }\end{array}$ \\
\hline
\end{tabular}


Table 2. Carney's (1994) framework for critiquing art and its application to the rich pictures in Figures 8 and 9.

\begin{tabular}{|c|c|c|c|}
\hline Step & Name of step & RP A (Figure 8) & RP B (Figure 9) \\
\hline 1 & Locate the Style & $\begin{array}{l}\text { Context is indicator influence in sustainable } \\
\text { development in the EU. RP is very focused on this. }\end{array}$ & Context is indicator use in agricultural development \\
\hline 2 & Descriptive Features and Structures & $\begin{array}{l}\text { Pictures has a number of components but they are } \\
\text { all related. Good use of colour. }\end{array}$ & $\begin{array}{l}\text { Picture has a number of components with good use of } \\
\text { colour. }\end{array}$ \\
\hline 3 & Primary Aesthetic Features & $\begin{array}{l}\text { There are a couple of prominent images. The see- } \\
\text { hear-speak no evil to the left of the picture, the } \\
\text { puppet to the right and the dominance of economic } \\
\text { indicators is at the centre. The bottom of the } \\
\text { picture has a representation of the globe and } \\
\text { tucked away at the very foot at the 'hidden' } \\
\text { indicators of sustainability }\end{array}$ & $\begin{array}{l}\text { Picture has basically two halves; from the 'bad' of the top } \\
\text { right (pollution, damage to agriculture) to the 'good' of the } \\
\text { bottom left (control of pollution, better agriculture). A river } \\
\text { connects the two ends. People are at the centre and } \\
\text { towards the bottom there is an economic angle which is } \\
\text { influencing the other components. The Yin and Yang } \\
\text { diagram, prominent towards the centre-top, highlights this } \\
\text { contrasting of worlds. }\end{array}$ \\
\hline 4 & Value Features & $\begin{array}{l}\text { The components have not been linked per se but } \\
\text { there are overlaps and the images have been } \\
\text { 'placed' into spaces which relate to each other } \\
\text { rather than having a sense of being separate } \\
\text { stories. }\end{array}$ & $\begin{array}{l}\text { The river links the two halves of 'bad' and 'good', as indeed } \\
\text { does the Yin and Yang image and money towards the foot of } \\
\text { the picture. The river also serves to illustrate the impacts of } \\
\text { pollution. }\end{array}$ \\
\hline 5 & Low-level Interpretation & $\begin{array}{l}\text { Picture has a strong focus on the perceived } \\
\text { dominance of economic indicators and their } \\
\text { precedence over sustainability indicators. The latter } \\
\text { are 'in' the scene but not apparent. This is very } \\
\text { much the primary theme - the focus of the story. }\end{array}$ & $\begin{array}{l}\text { Picture doesn't seem to say all that much. The highlighting } \\
\text { of the importance of pollution is fine but that is not much of } \\
\text { a story. Indicators are absent from the picture as indeed is } \\
\text { any appraisal of their influence (what the picture should be } \\
\text { about). }\end{array}$ \\
\hline 6 & High-level Interpretation & $\begin{array}{l}\text { During the plenary the group highlighted this sense } \\
\text { of economic indicators dominating over } \\
\text { sustainability indicators }\end{array}$ & $\begin{array}{l}\text { During the plenary the group were asked about the absence } \\
\text { of indicators in their picture and basically put it down to } \\
\text { confusion amongst the group. }\end{array}$ \\
\hline 7 & Critical Judgment & $\begin{array}{l}\text { A strong RP that tells a clear, coherent and focussed } \\
\text { story }\end{array}$ & $\begin{array}{l}\text { A weak RP that does not address the question and which } \\
\text { says very little other than pollution is bad for the } \\
\text { environment and agriculture. }\end{array}$ \\
\hline
\end{tabular}

